\title{
Erratum to: 'Comparison of calculated and experimental power in maximal lactate-steady state during cycling'
}

Thomas Hauser $^{1 *}$, Jennifer Adam ${ }^{1,2}$ and Henry Schulz ${ }^{1}$

* Correspondence: Thomas.Hauser@gmx.de

${ }^{1}$ Chemnitz University of Technology, Chemnitz, Germany

Full list of author information is available at the end of the article

\section{Erratum}

Unfortunately, the original version of this article [1] contained errors. In equation 7, where ADP-concentration is calculated based on VO2ss and VO2max (Calculation of free ADP-concentration with respect to activated oxidative phosphorylation and maximal oxygen uptake): the term "Ks2" is being changed to "Ks1" (Ks2 is wrong within the equation).

In the sentence before equation 7 :

Wrong (current) version:

"If $\mathrm{V}^{\cdot} \mathrm{VOss}$ is known or easily fit from 1 to $\mathrm{VO} 2 \mathrm{max} \mathrm{V}^{\cdot} \mathrm{O} 2 \mathrm{max}$, Equation 2 can be rearranged in Equation 7. Therefore ADP-concentration can be calculated for a special workload depending on $\mathrm{VO} 2 \mathrm{ss}_{\mathrm{V}}{ }^{\circ} \mathrm{O} 2 \mathrm{ss}$ and $\mathrm{VO} 2 \mathrm{max} \mathrm{V} \cdot \mathrm{O} 2 \mathrm{max}$, in the form of..."

\section{Correct version:}

The number is changing from equation 2 to equation 3 as shown below:

"If VOss $\mathrm{V}^{\cdot} \mathrm{O} 2 \mathrm{ss}$ is known or easily fit from 1 to $\mathrm{VO} 2 \mathrm{max} \mathrm{V}^{\cdot} \mathrm{O} 2 \mathrm{max}$, Equation 3 can be rearranged in Equation 7. Therefore ADP-concentration can be calculated for a special workload depending on VOss $\mathrm{V}^{\cdot} \mathrm{O} 2 \mathrm{ss}$ and $\mathrm{VO} 2 \mathrm{max} \mathrm{V}^{\cdot} \mathrm{O} 2 \mathrm{max}$, in the form of..."

\section{Author details \\ ${ }^{1}$ Chemnitz University of Technology, Chemnitz, Germany. ${ }^{2}$ Department of Internal Medicine/Cardiology, University of Leipzig, Heart Centre, Leipzig, Germany.}

Received: 30 August 2016 Accepted: 30 August 2016

Published online: 08 September 2016

\section{Reference}

1. Hauser T, Adam J, Schulz H. Comparison of calculated and experimental power in maximal lactate-steady state during cycling. Theor Biol Med Model. 2014;11:25. 